\title{
Striving for 'walk-away' — focusing an expert group on the 'holy grail' of mine closure
}

\author{
M.B. McLeary Department of Primary Industries and Resources South Australia, Australia
}

\begin{abstract}
Leading practice 'mine closure' is now integral to mine planning from inception. However, in an historic site there is limited opportunity to gain site knowledge and integrate closure planning throughout the life of the mine. Acid metalliferous drainage (AMD) at Brukunga Mine, 90 minutes east of Adelaide, South Australia, is a significant long-term environmental issue as a consequence of pyrite mining - with the site now comprising two large waste rock dumps, a tailings dam, mine benches and voids, all containing sulphidic material. Past and current predictions are that generation of AMD could require ongoing treatment for 300 to 1,000 years. The South Australian Government has managed this site since 1977 and costs are approximately A $\$ 1 \mathrm{~m}$ per annum. The Department of Primary Industries and Resources South Australia (PIRSA) is currently implementing a process for determining the most effective long-term solution for site remediation.

A review of the current mine management strategy was undertaken in 2007, resulting in the development of the Brukunga Mine Forward Program, comprising six phases. Phase 1 included the establishment of a technical advisory group (TAG), tasked with recommending (to Government) the most effective technical 'walk-away' remediation solution for Brukunga Mine. The TAG provides some 125 years of combined national and international experience specialising in geochemistry and water treatment; geotechnical aspects and soil covers; and remediation options and costing ${ }^{1}$. The group developed potential 'walk-away' remediation solutions by functioning under a guided self-management model. This model incorporated shared information, shared decision-making, application of selected expertise across different companies/agencies, and group developed models to generate creative and holistic solutions to complex problems. The TAG operated independently but under overarching guidance applying a variety of technologies and process strategies including meeting in workshops, online, on-site and in teleconference environments at frequent intervals.

Validation of the TAG process and guided self management model, is demonstrated by an agreed notion that 'walk-away' remediation is realistic and achievable, by delivering a preferred 'walk-away' remediation option to Government and thereby ensuring commencement of Phase 2 (testing, feasibility of the option) of the Forward Program. The focus of this paper is to illustrate the process by which the TAG functioned and developed such a 'walk-away' solution at Brukunga Mine. Ultimately, committing to and implementing any 'walk-away' remediation of AMD at Brukunga Mine rests with future Government.
\end{abstract}

\section{Introduction and brief history of remediation at Brukunga Mine site}

Current leading practice ensures mine closure forms an integral part of mine planning from its inception through operations to completion. The major difficulty in Government taking ownership of an historic site with environmental concerns, is the inability to gain intimate site knowledge and integrate closure planning (including costs) throughout the life of the mine, implicit in modern management of mines.

AMD at Brukunga Mine is a significant, long-term environmental issue for the minerals industry and the public at large. As a consequence of pyrite mining from the 1950s to the 1970 s by a publicly listed mining company the site now comprises two large waste rock dumps containing sulphidic material, a tailings dam comprising sulphidic sand-size tailings, and mine benches and voids (Figure 1). Past and current predictions

\footnotetext{
${ }^{1}$ TAG members: Peter Scott and Jeff Taylor (geochemistry); David Williams and Mike O'Kane (geotechnical); David Brett (remediation and costing); and de-facto chair Michael McLeary.
} 
are that the generation of AMD could continue for at least 300 years (ANSTO, 1994) and up to 1,000 years (TAG pers. comm., 2007), requiring ongoing water treatment. The South Australian Government has managed this site since 1977, five years after mining had ceased, and the current site management and plant operation costs are of the order of $\$ 1 \mathrm{~m}$ per annum.

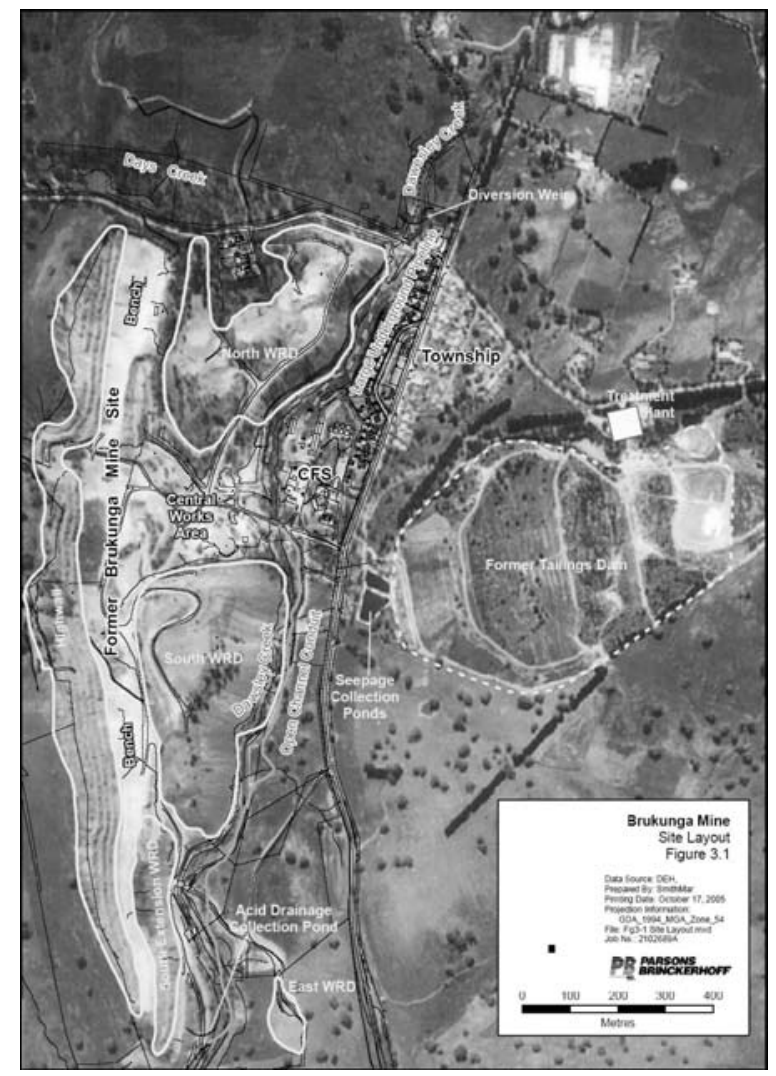

Figure 1 Brukunga Mine site depicting site layout and sites of AMD generation

The Brukunga Taskforce, and later the Brukunga Mine Site Remediation Board (BMSRB), were established to examine the ongoing AMD problem and to develop a strategy for remediation. In June 2001, a 10 year rehabilitation programme comprising three stages was recommended and accepted by State Cabinet. The approved strategy has been progressively implemented, with the present state of progress as follows:

- Stage 1: Diversion of Dawesley Creek to reduce acid loads - completed in June 2003.

- Stage 2: Increase Water Treatment Plant Capacity to upgrade and improve efficiency of acid treatment and reduction of sludge - completed in May 2005.

- Stage 3: Relocation and Rehabilitation of Waste Rock Dumps designed to reduce a source of acidity and metals - not yet commenced.

The planned Stage 3 strategy originally focussed on the relocation of the waste rock dumps, but not on the ongoing acid drainage from the tailings dam or other areas of the mine, thus requiring the operation of a water treatment plant in perpetuity. A review of the present mine remediation management strategy was undertaken in 2007, resulting in the development of the Brukunga Mine Forward Program. The Forward Program was designed to be implemented prior to the commitment of capital funding for Stage 3, to ensure that leading practise options would be considered and implemented thereby maximising benefits to the public and the environment.

The Forward Program was built around four key strategies:

- Reconsideration of the strategic goals for rehabilitation of Brukunga Mine.

- Experimental trials of various treatments on Brukunga Mine waste rock samples. 
- The utilisation of recognised national and international experts to develop remediation options through a TAG.

- Continued community engagement.

The Forward Program is a six phased program of which Phase 1 is the establishment of a TAG. The TAG is tasked with reviewing and recommending (to Government) the most effective technical remediation solution(s) for the Brukunga site. Given the complex and varied problems of landscape and mining related AMD at Brukunga over the past 60 years, and the potentially damaging aspects of AMD generation into the future, a successful remediation programme leading to mine closure is a reasonable community and Government expectation. The Forward Program, and particularly the TAG by its technical function, offered that potential solution. The purpose of this paper is to outline how the TAG, through a 'guided selfmanagement model', appears to have achieved both the hopes and expectations of achieving a 'walk-away' remediation solution at Brukunga Mine site.

\section{Rationale for the TAG}

In developing both the methodology and makeup of the TAG, the decision making process was guided by the following considerations:

- Previous attempts at seeking cost effective lasting solutions, whilst providing robust discussion and innovative possibilities, were limited in both direction and guidance, and thus had been discontinued.

- Given the complexities of the site, existing expertise within Primary Industries and Resources of South Australia (PIRSA) and the technical groups within the South Australian Government was considered insufficient. Furthermore, it was felt that no individual company/organisation could offer the calibre of expertise that would be required across all areas. There was also a risk that a single company/group might potentially end up deviating from PIRSA's identified objectives.

- Most importantly, it was felt that prior to taking options to a broader audience, a purely technically focussed range of options (based on the constraints and limitations of the site) should be developed i.e. only forwarding what could technically be feasible. This ensured the community would not be presented with false expectations of what may or may not be achievable.

The composition of the TAG was chosen firstly to establish the building blocks of a structurally and chemically sustainable landform. Other areas of expertise, whilst also considered highly valuable, would be called upon during the feasibility and planning and design phases in order to meet the key objectives.

Additionally, the required technical expertise was chosen from wherever it was available, not just from a specific consulting firm. A key strength of the process adopted at the Brukunga Mine, is that senior specialists from several companies were engaged and encouraged to work together to develop mutually agreeable remediation options and a mutually agreed strategy to define a preferred option. There are subtle psychological benefits of this approach, not outlined here, but suffice to say that it is an effective way of bringing the best out of all, and ensuring that all work together collaboratively.

Following a national and international call for expressions of interest, five leading experts in the field of AMD and mine site remediation were invited to form the TAG. The group selected provide 125 years of combined national and international experience and comprised two specialists in geochemical aspects and water treatment; two specialists in geotechnical aspects and soil covers; and one specialist in remediation options and costing.

The process model to be applied to ensure the most effective functioning of the group was a major consideration. Models applied to other mine closure group processes have generally incorporated strategies such as chaired groups and or risk management approaches. For Brukunga, given its complexities, numerous past reports, repeated attempts at remediation with limited success and the repeated delay and lack of progress with past closure management attempts, a different approach was deemed necessary.

To this end, government control of the TAG was lessened and a collegiate egalitarian approach encouraged, but with guidance to allow for both rigour and flexibility. In essence, there was no chair of the TAG, although a technical facilitator was used to assist in synthesising and documenting key points emerging from 
discussion. The discussion components were non-hierarchical in that no one TAG member was allowed to dominate and assume the role of de-facto chair of the group. Management of the group was therefore by consensus, by group agreement. This applied to all components including: when and where to meet, site visits, site testing, the format of written documents and reports, and for all recommendations back to Government.

Guidance of the process was through the project manager ${ }^{2}$ and facilitator to advise when the group was moving outside of the terms of reference (TOR) if that occurred, if costs were being exceeded, and on Government policy and procedure when required. This model of function prevented members from being constrained by previous approaches, or by previous reporting and findings, and allowed members full creative opportunity to develop remediation solutions from a sound and original base. The TAG was encouraged to develop whatever remediation solutions they saw as workable in an environment of technical and bureaucratic freedom, and without interference of past or Government baggage.

Within this group function model the TAG was required to refine the objectives towards developing a 'walkaway' solution to AMD from Brukunga. The TAG was supported by a small team ${ }^{3}$ who undertook tasks, research, scoping, etc. on their behalf. In a similar sense to mine closure processes, the term 'walk-away' is comparable to 'mine completion' where not only “... ownership can be relinquished and responsibility accepted by the next land user", but also the resultant landform will "... prevent or minimise adverse longterm environmental, physical, social and economic impacts" (DITR, 2006). The definition of 'walk-away', initially established by PIRSA and later refined by the TAG, was therefore deemed to be ...

\section{... remediation allowing return of the land to a land use suitable for release of the land from government ownership such that the site requires no further intervention by, ongoing responsibility for or cost to government and/or community.}

The TAG's mission therefore was "to provide independent assessment, opinions and recommendations to effect a cost effective final solution that meets or exceeds all of the overall project objectives" for remediation of the Brukunga Mine site, to a 'walk-away' criterion, by the required deadline. This ensured that allocated monies could be effectively and efficiently expended in achieving a successful closure and completion strategy for the Brukunga site. The overall remediation objectives for the Brukunga Forward Program that comprised the 'walk-away' criterion, and refined by the TAG, were to:

- Improve water quality in Dawesley Creek to a standard that complies with the EPA water quality policy.

- Substantially limit or avoid the need to intercept and treat acid waters indefinitely.

- Return all or part of the site back to productive use(s) or for environmental/ecosystem value(s).

- Apply leading practice to site management and the remediation option(s) and solution(s).

The broad process phases and indicative timeframes required to enact a final closure (mine completion) of the Brukunga Mine site, to the proposed 'walk-away' standard, were as follows:

- Phase 1: Establish the TAG; undertake remediation option investigation - completed November 2008.

- Phase 2: Remediation option definition/feasibility.

- Phase 3: Planning and design (to follow approval of remediation option definition phase).

- Phase 4: Construction/mine closure.

- Phase 5: Post-closure monitoring.

- Phase 6: Validation and completion.

\footnotetext{
${ }^{2}$ Project Manager: Michael McLeary

${ }^{3}$ PIRSA support: Bev Voigt, Molly Carrigan, Ross Stevens, Paul Foster, and Monica Redden.
} 
The TAG has been an active participant in the early phases and may continue to be active in some of the later phases. The key features of the Forward Program, incorporating the TAG and the model that underpinned the TAG's development of a preferred option for remediation of AMD at the Brukunga Mine, have been conceptualised and summarised (Figure 2).

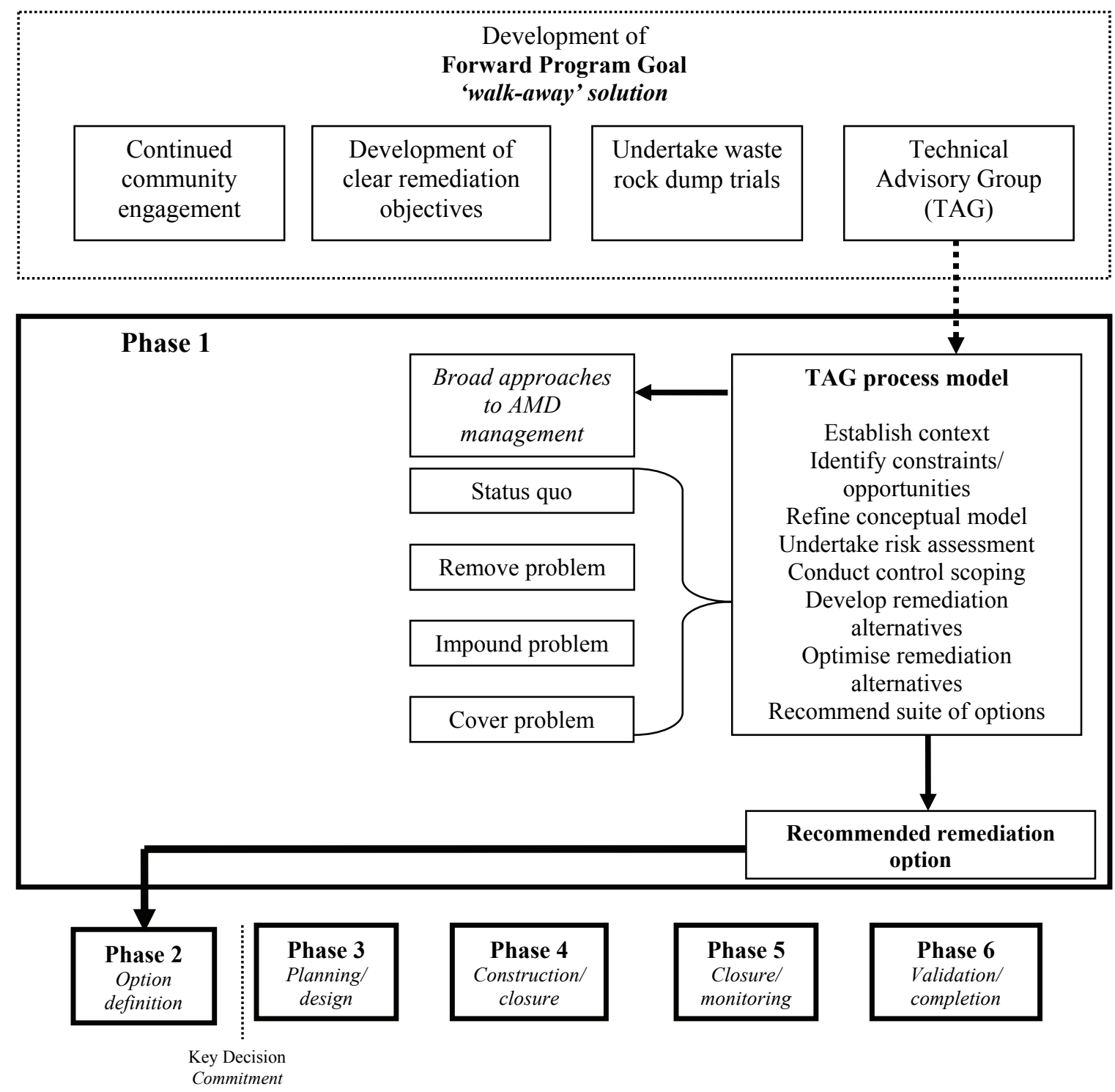

\section{Figure 2 Forward Program flowsheet}

\section{TAG guided self-management model}

The TAG used a guided self-management model in determining the most effective long-term remediation solution for the site. The model provided a framework that accommodates creativity, forward thinking, planning and testing. Under this model the multi-specialist TAG was required to move in a mostly linear sequence of broad areas or stages, but allowed also to move laterally without sacrificing creatively within each stage of the process, as well as vertically to and from each major stage. 
At the inaugural TAG meeting, the TAG developed and agreed to a series of work process steps, including:

- Establish the context, and familiarise with the site.

- Review constraints and opportunities, including data gap analysis and critical data.

- Develop, populate and refine a conceptual model that represents a realistic description of the site and surrounding inputs and outputs.

- Conduct an environmental risk assessment on the site to prioritise remediation options.

- Undertake control scoping, along with brainstorming any potential remediation options.

- Assess alternative options, and conduct sensitivity analyses and preliminary cost estimates.

- Optimise alternative options: including a residual risk assessment, refinement of costs to $+/-30 \%$ and measuring against a do nothing option.

- Recommend up to six remediation options reflecting the highest technical and scientific standards representing current leading practice trends nationally and internationally in the management of acid and metalliferous drainage.

Key strategies in implementing this guided self-management model were:

- The development of clear and technically relevant TOR including definitions, goals and specific objectives.

- The inclusion of an overarching goal in the TOR, i.e. to develop the 'walk-away' remediation solution for the site, measured against both the do nothing and ongoing and current water treatment/status quo options. Note: the do nothing option is effectively theoretical and refers to turning the treatment plant off and leaving the site to return to the pre-intervention state.

- Provide a suitable unconstrained forum for the TAG to discuss and define the criteria for 'walkaway' in relation to technical parameters.

- Developing an agreed to 'decision making plan', which included the means by which decisions would be carried forward to ensure that project and Government objectives would be met.

- Creating the opportunity to discuss and review technical data as available in a small group, via remote teleconference, via online sharing and via field visits to the Brukunga Mine site, at regular and frequent intervals throughout the process.

- Delivery of an interim and a final report that summarised the decision making process and a suite of potentially final long-term remediation technical solution(s), along with an identified preferred solution.

A brief review of each stage in this guided self management model process for Phase 1, provides illustrative examples of how the integrated mixed specialities of the TAG developed solutions to the complex and longstanding environmental problem at Brukunga Mine, which is of major local significance. The TAG achieved this with a combination of objective guidance, retrospective analysis, planning and predictive modelling, and forward planning with projected calculations on acidity, management and costs, and a commitment to shared knowledge and team decision making.

\subsection{Step 1 - Establishing the context: sixty years of reports on remediation}

This stage required the group to investigate retrospectively the history of the site pre-mining, during mining and post-mining until the present. This included reviewing all available information on history and features, key elements of the site, geology, climate, hydrology (catchment, surface and groundwater), geochemistry, geotechnical and previous remediation strategies and proposals. The importance of this phase was two-fold: 
- To ensure all members of the TAG were thoroughly briefed and had a similar understanding of background information from which to move forward and commence creative planning.

- To restrain each member from moving immediately into proposing any preconceived notions regarding solutions to the AMD problem. The latter point was particularly significant as more than one member of the TAG, even at that early period, were suggesting remediation options without the benefit of group consideration and thorough analysis of available past data.

The major outcome from this stage was an assessment of the available literature and the subsequent production of a guide to future project activity. The difficulty for the TAG was to determine and agree on which reports and which data were still relevant today, which data were incomplete, and which areas required new investigation.

The reports and data amassed for the Brukunga Mine site were synthesised into discrete groupings: water quality monitoring reports; technical reports on water treatment; rehabilitation technical reports and reviews; geological and mineralogical studies; and a multitude of summary reports. As a consequence of the critical review of the available information, a comprehensive gap analysis was produced which provided the basis for further information gathering, field testing and or reanalysis for future stages.

\subsection{Step 2 - Aspects of the site: constraint or opportunity?}

Emanating from the review of the available data on the Brukunga Mine site, various constraints and opportunities in relation to the remediation of the site were initially identified and documented by the TAG in each of the process phases followed. During the course of the TAG process, many of these constraints came to be seen as opportunities, e.g. the potential use of oxidised tailings as cover material.

Where absent data were required as part of the TAG process, the group returned again to the TOR which clearly set out a process aimed at ensuring that only critical data would be collected. This reduced the possibility of potentially irrelevant or overly narrowly focussed studies and investigations being implemented. The recurring question was always "why are we doing this, what will it tell us and do we really need it?"

\subsection{Step 3 - Conceptualising site models: which model for which prediction?}

Early conceptual models of the site were described in a number of reports, stimulating theoretical and practical discussion as to the potential remediation strategies with respect of various on-site AMD causality and consequence processes. The TAG considered that some of the existing models were (for the most part) adequate, and after careful consideration only minor amendments were made to bring these up to current thinking (Figure 3). This model then set the standard against which various site related issues could be measured and, in terms of remediation, allowed the base for these to be built. The model was continually revised throughout the remaining stages.

A strategy applied during this stage was repeated with visual modifications to maps and previous conceptual models - either depicted as crude graphics, as schematic diagrams, or as GIS overlays. The visual alterations allowed for theoretical considerations to be brought back to realistic adaptations of the real Brukunga world, i.e. as pragmatic alterations within a geographical and geochemical puzzle. This also allowed all TAG members to continue working along the same conceptual map of the AMD rather than be allowed to move into corners of expert knowledge. 


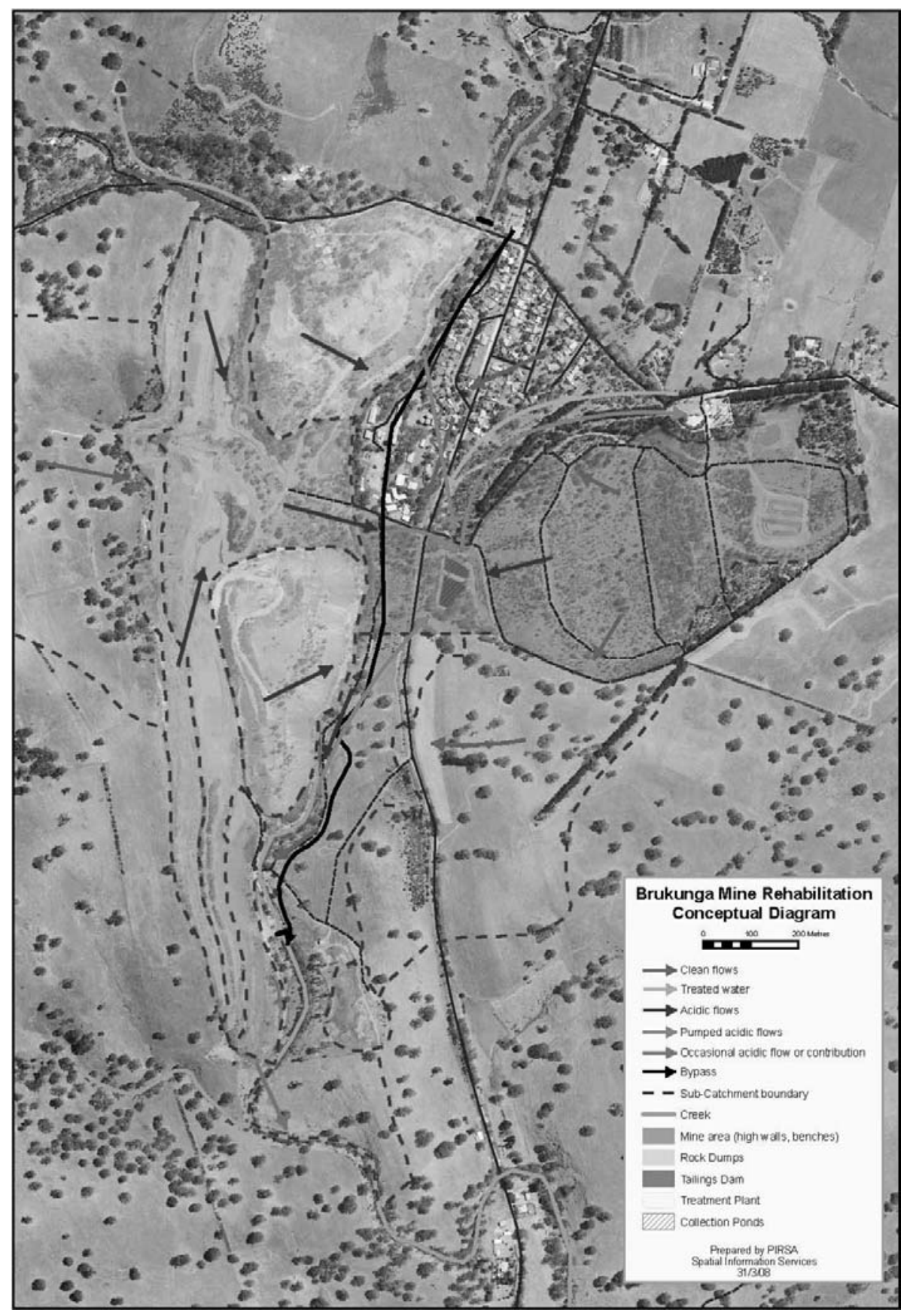

Figure 3 Brukunga Mine site - example conceptual model

\subsection{Step 4 - Risk assessment: not simply one-dimensional}

This was considered the most important stage of the process, especially given that many mine closure programmes embrace standard risk assessment processes within their overarching framework. The TAG recognised there are many definitions of risk, and a variety of these needed to be considered in developing a suite of potential remediation options.

The Best Practice Environmental Management in Mining booklet (EA, 1999) describes risk as having two dimensions: 'consequence' and 'likelihood', and defines risk as the likelihood of actual harm, as distinct from 'hazard', which is defined as a potential cause of harm. Risk analysis, according to the TAG, allowed quantification of the options, and of the likelihood, consequences and costs of failure. The 'overall risk ranking' eventually adopted by TAG, required agreement on both definition and strategy, and therefore needed to incorporate the cumulative product of the likelihoods and the consequences of all causes or failure 
modes. As a consequence of the TAG self-managed model, new strategies for analysing risk were developed and applied to a number of other stages.

Consequently, this stage generated debate, consternation, frustration and creativity. Ultimately, the TAG defined the aim of the risk assessment of Brukunga Mine site to be: to identify the acceptability or otherwise of each hazard. Those hazards identified as presenting an unacceptable overall risk ranking were to be targeted for remedial action, while hazards presenting a low overall risk ranking would not benefit greatly from remediation expenditure.

The overall risk ranking was expressed in the form of a matrix of likelihood and consequence, either quantitatively or semi-qualitatively (for example, as presented in Figure 4, selecting a 0 to 5 scale in this case; where NPV = net present value, and ORR = overall risk ranking, for various remediation options). The risk ranking also included a cost component, to allow consideration of the cost-effectiveness of any remediation (Figure 4).

Was this consideration of risk different to other forms of risk assessment for mine closure? The technical risks at Brukunga were most probably similar to many other AMD sites, in that they:

- Needed to be measured over a long period of time.

- Were complex in nature.

- Could be affected by natural events.

- Needed to account for the frequency and degree by which local changes were likely to occur.

Hence, a number of options needed to be assessed and ranked, not just in terms of the risk of failure, but also in terms of the risk of change over time. Ultimately, the approach to risk management was probably not dissimilar to other mine closure risk assessments. However, the generation of the overall risk rankings was achieved by a grouping of professional disciplines, all of which brought a different perspective and a different type of expertise to the risk ranking process. The upshot of the group approach to risk ranking was therefore more considered and holistic, but still founded upon technical parameters.

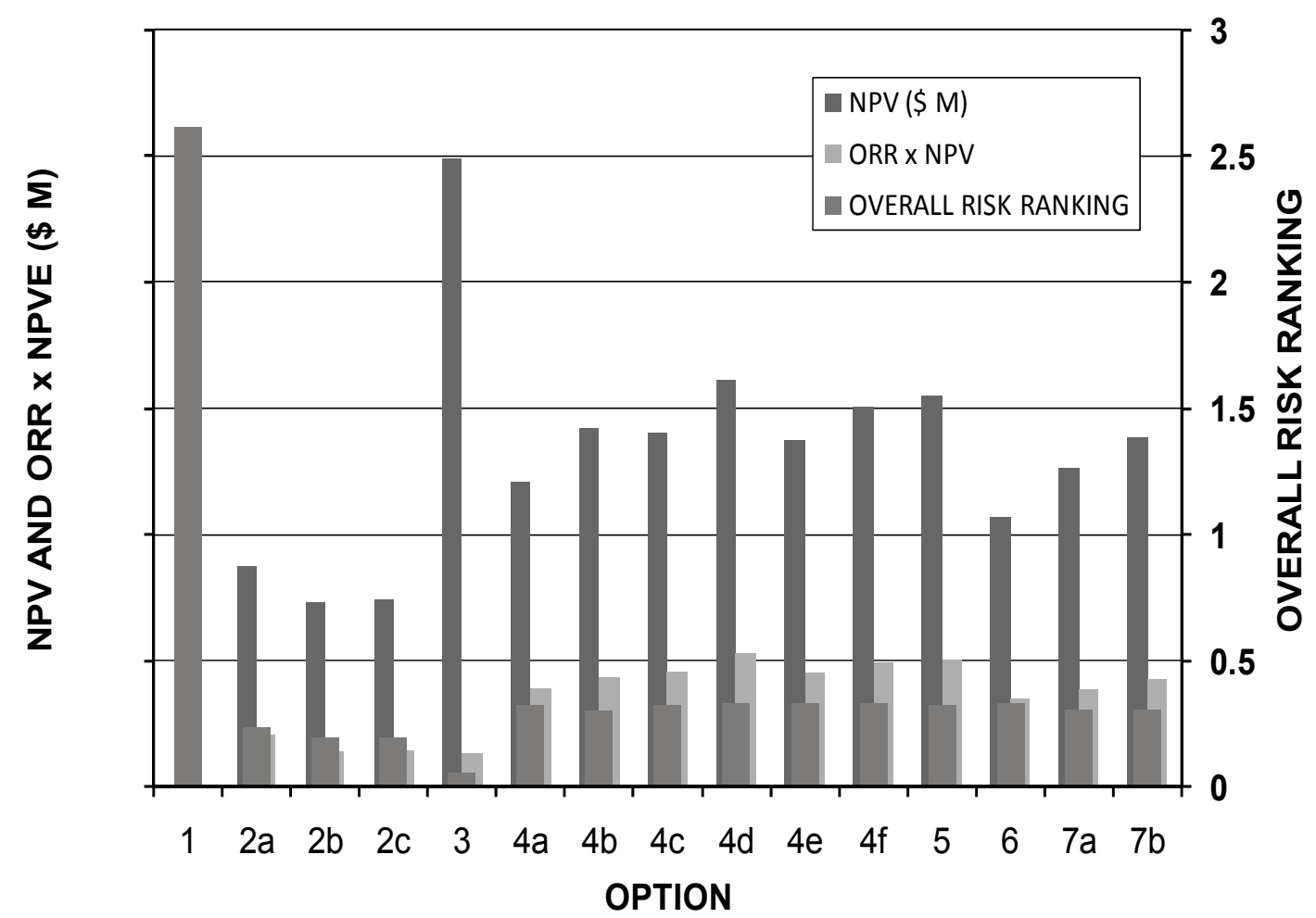

Figure 4 Example chart of risk assessment/cost effective analysis of remediation options, Brukunga. $\mathrm{NPV}=$ net present value; $\mathrm{ORR}=$ overall risk ranking 


\subsection{Step 5 - Scoping the options: considering the artist's palette}

Control scoping incorporated an investigation of the broad themes of remediation approaches to AMD. The TAG identified four major approaches:

- Maintaining the status quo, i.e. ongoing water treatment.

- Removing the cause of the problem by transferring the source of the AMD off-site.

- Containing the source of the AMD on-site.

- Covering the cause of the AMD and rendering it inert.

Combinations of these four approaches were seen as acceptable possibilities. Each option in turn was measured against the do nothing (theoretical base case) option, i.e. turn the water treatment plant off, effectively allowing the site to regress to the post-mining/pre-intervention state. This scoping phase was instrumental in the creative development of the suite of more than 15 potential remediation options.

\subsection{Steps 6 and 7 - Developing, optimising remediation options: painting a blank canvas}

The TAG identified 15 possible remediation options for the Brukunga Mine site, grouped into the following general types of options:

- No management/remediation option, i.e. do nothing about the AMD on-site including no water treatment (option 1).

- Water treatment options, including maintaining the status quo (options 2a, 2b, 2c).

- Relocating waste and other cleanup options (option 3).

- Cover options, including methods to reduce drainage by reducing exposure to oxidation (options $4 \mathrm{a}$, $4 \mathrm{~b}, 4 \mathrm{c}, 4 \mathrm{~d}, 6)$.

- Containment options, aimed at containing the waste material to prevent escape from site (options $7 \mathrm{a}$, $7 b)$.

- Combination options, which include various combinations of the above (options 4e, 4f, 5).

Models were developed for each remediation option or group of options, e.g. Figure 5. The production of models was important in translating the theoretical and data related materials into a mapped and practical model. This was achievable as a consequence of the combined intellectual and practical field strengths of the TAG.

This complex exercise allowed TAG members, individually and as a group, to develop comprehensive modelling and precise predictions with a 'holistic' geological-geotechnical-geochemical basis, in the foundation of the suite of options created. By this stage (over 12 months in duration), the group was selfmanaging in task allocation, communicating well and calling teleconferences to discuss contentious and taxing intellectual issues. The strengths of each of the TAG members were well understood and, as a consequence, the efficiency of development and documenting the remediation options was rapid and productive. The adage 'the whole is greater than the sum of the parts' is applicable too and the most important process feature of these stages. 


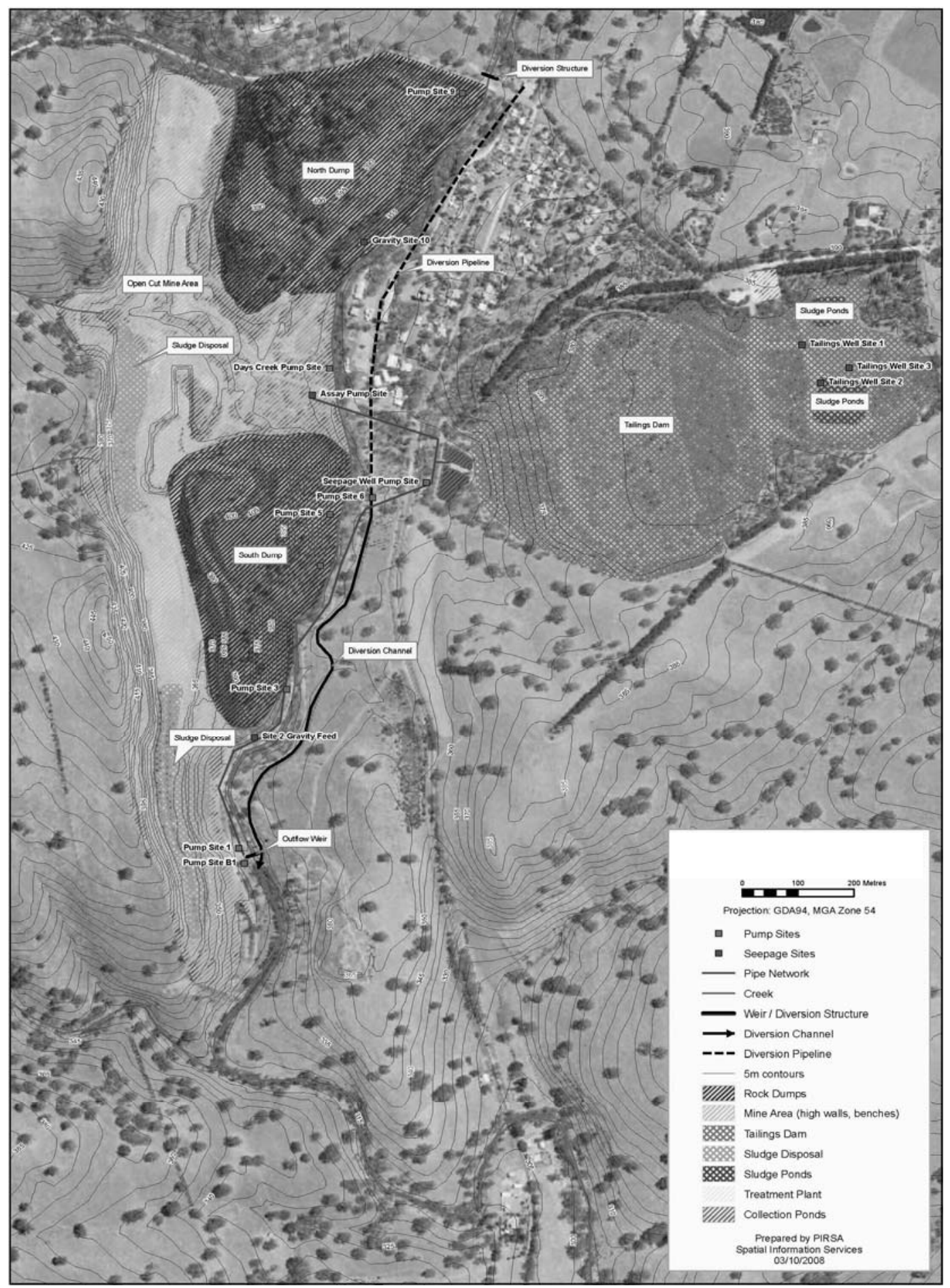

Figure 5 Example remediation option model: 'continue current treatment'

To optimise and discriminate between options, a return to the TOR and the original objectives was always the first consideration of the TAG. In this instance, the water quality, downstream of the mine was considered the ultimate test of the effectiveness of a remediation option. If an option provided for long-term acceptable water quality (meeting EPA requirements), then it was deemed to be effective and essentially met the quality/quantity requirement of the objectives. To this end, the TAG developed a 'water quality dilution model' to test each remediation option (Table 1). Essentially the water quality dilution model was based on a spread sheet, mathematically formulated to enable acidity and metalliferous production using actual data to be determined for each remediation option. This output was compared with a set of reference figures (based on the EPA figures) and an overall risk ranking for each remediation option determined. 
The outcome of the performance of each option provided a ranking of effectiveness and allowed filtering of suitable and unsuitable options, at least to a certain level. Further prioritising of options was continued in relation to cost and to other related Government regulations or associated community needs. Most importantly, the 'water quality dilution model' (a by-product of the risk assessment stage) provided the opportunity for the TAG to identify within the suite of remediation options developed, those that were 'walkaway', in that the option would (as determined by TAG) produce discharge water from the mine which would meet EPA requirements for the foreseeable future, without the need for further management from Government and with no additional cost.

Table 1 Example 'water quality dilution modelling' of remediation options at Brukunga Mine site

\begin{tabular}{llll}
\hline Option No. & Description & Average Acidity (mg/l caco ${ }^{\mathbf{~ e q} .)}$ & Walk-Away Solution? \\
\hline $\mathbf{2 a / b} / \mathbf{c}$ & $\begin{array}{l}\text { Continue water treatment } \\
\text { ('status quo') }\end{array}$ & 124 & No \\
$\mathbf{3}$ & Relocate wastes off-site & 250 & Yes \\
$\mathbf{7 a}$ & Containment option & 255 & Yes \\
$\mathbf{7 b}$ & Containment option & 277 & Probably \\
$\mathbf{6}$ & Cover option & 315 & Probably not \\
$\mathbf{4 e}$ & Cover option & 348 & No \\
$\mathbf{4 f}$ & Cover option & 348 & No \\
$\mathbf{4 c}$ & Cover option & 409 & No \\
$\mathbf{4 d}$ & Cover option & 409 & No \\
$\mathbf{4 a}$ & Cover option & 450 & No \\
$\mathbf{4 b}$ & Cover option & 450 & No \\
$\mathbf{5}$ & Original 2001 option & 1418 & No \\
$\mathbf{1}$ & No water treatment or & 1483 & No \\
& remediation ('do nothing') & & \\
\hline
\end{tabular}

\subsection{Step 8 - Recommend preferred remediation options}

The final stage of the TAG process involved the recommendation of one preferred option from the 15 options that had been developed to put to the Government for further consideration, validation and 'proving'. This task required the TAG to consider and apply the risk assessment model as developed in an earlier phase, the costing of the options as developed earlier, the application of the water dilution model, the constraints and opportunities that had arisen during the 18 month journey through the process, but ultimately the key goal as referred to in the TOR, the notion of 'walk-away'. Only those options that adhered to the definition of 'walk-away' could be considered and ultimately one was put forward by the TAG as the preferred remediation option (Figure 7). The TAG decision-making process was by consensus and according to that key goal. The group presented the evidence of their decision and their recommendation to the Government in November 2008.

The elements of the remediation option that was recommended to Government included:

- 'Walk-away' potential - one of only three possible 'walk-away' solutions that were developed.

- Flexibility with respect to geotechnical and geochemical strategies.

- Was the most cost effective strategy in relation to outcome.

- Provided the most flexible outcome in relation to final landforms.

- Achieved very good water quality outcomes with respect to EPA guidelines. 


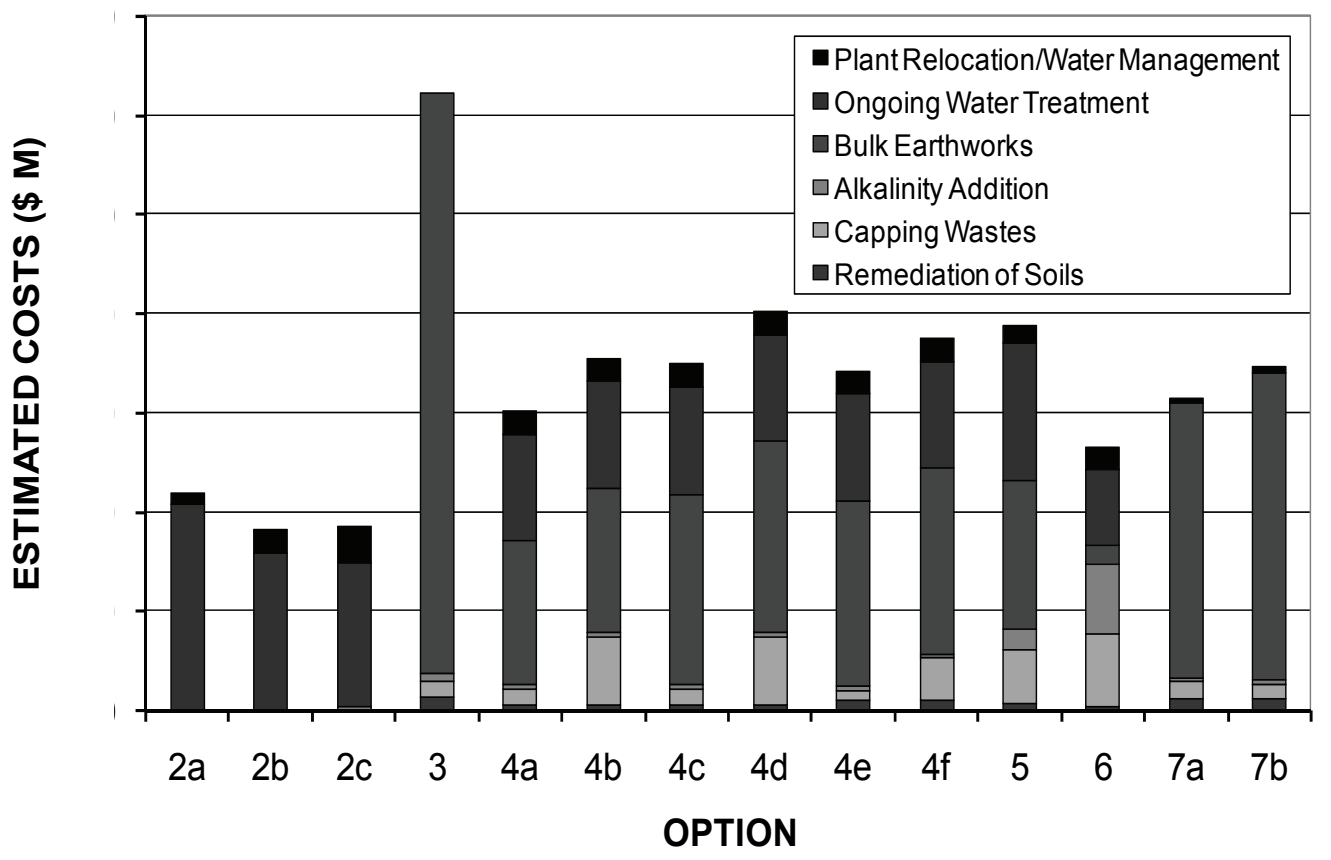

Figure 6 Example cost comparison chart for determining preferred remediation option at Brukunga Mine site

\section{$4 \quad$ Gauging success of the guided self-management model by TAG}

The goal of the TAG was to assess the potential for a 'walk-away' remediation strategy for the Brukunga site, measured against the 'do nothing' and ongoing water treatment options. The measurable criteria assigned to any remediation option developed by the TAG included:

- Meeting water quality standards that complied with EPA Policy.

- Limiting or avoiding the need to intercept and treat acid waters indefinitely.

- Returning the site back to productive use or environmental value.

- Applying leading practice to site management and remediation solution(s).

Achieving a recommended remediation option enabling Phase 2 to proceed is an important component of success at this stage. Generating a range of remediation options is a relatively easy task, but refining those to a single workable option, universally regarded (by all TAG members) as potentially 'walk-away', is difficult. Success of the process would also have been achieved if the TAG had decided no 'walk-away' strategy was possible. However, in this instance not only was the process considered successful, but the bonus was there was consensus that a potential 'walk-away' solution had been found.

Evidence of the success and importance of the TAG and the approach taken, was demonstrated by a number of significant findings arising as a direct consequence of the seeking of a 'walk-away' solution to management of AMD from Brukunga. Firstly, the TAG process and an associated waste rock trial, demonstrated that a previously developed remediation strategy for the Brukunga site, proposed in 2000/2001 (PIRSA, 2001), and involving wholesale limestone blending with the waste rock, would most likely have been unsuccessful, and potentially cost the community many millions of dollars. The implications of this finding and the predicted failure of that model, has ramifications for the future development of long-term management strategies in relation to AMD, both at Brukunga and for other sites. Secondly, previous attempts at seeking cost-effective lasting solutions, whilst providing robust discussion and innovative possibilities, were limited in both direction and guidance, and thus discontinued. Finally, as a lesson to ensure that the site and its relevant issues are fully understood (prior to considering remediation options), it should be noted that 
some of the final remediation options being investigated further by the TAG include aspects of previously discounted options and ideas.

A number of other factors indirectly influenced the likelihood of a successful remediation option outcome. For instance, over the past decade, a change in both political and social attitudes to environmental matters, particularly those related to local pollution, was influential in convincing high level decision makers within Government, that remediation at Brukunga needed to occur and that maintaining the 'status quo' of perpetual water treatment was not a sustainable solution, or one the community would accept.

Furthermore, the Forward Program and in particular the TAG process, was supported at various other levels, including the State Government managing body (PIRSA), with endorsement of the BMSRB, and with in principle approval by other associated agencies (the EPA, local council, local community groups). In addition, astute and considerable preplanning by PIRSA in developing the Forward Program prior to committing to and implementing Phase 1, was in hindsight, an essential ingredient in achieving the optimum balance and mix of TAG expertise and character that allowed for the development of such a cohesive, harmonious and productive technical advisory group.

The final suite of factors and characteristics that facilitated a successful outcome for the TAG and their role in the process related more to direct strategies adopted by the TAG members and by the guiding project manager. Fundamentally, the TAG was constantly challenged by the goal presented to them (and acceptance of that challenge), on both technical and non-technical grounds, especially in relation to best practice procedure and to methods that would be resilient under adversity and over time, as required by a 'walkaway' outcome. Secondly, all workshops and teleconferences required full team participation and were characterised by scientifically focussed facilitation. These group workshops/teleconferences provided an unfettered and unconstrained platform to TAG members, when considering the various conceptual remediation options. Lastly, but importantly, the TAG developed a collective passion and impetus in meeting the challenge of developing this initially lofty, but later realistic and achievable, 'walk-away' solution.

The response from Government and the BMSRB to the results presented in the TAG final report, validating the efforts and the approach taken, was to immediately commence the plan for Phase 2; i.e. a detailed investigation of the technical feasibility of the preferred remediation option.

\section{Conclusions}

The formulation of a multi-skilled TAG, incorporating a blend of geochemical, geotechnical and engineering experts, has been instrumental in developing a suite of potentially 'walk-away' solutions to the problems of AMD at the Brukunga Mine site. The success of the TAG to date in meeting that goal, has been achieved in this instance by applying a self-managed model. This required the sharing of information and expertise to agree on solutions to complex problems; and shared agreement on those solutions most likely to meet 'walkaway'. The success of the group was facilitated by the creative whole of the group developed as a consequence of the unconstrained yet guided process, allowing freedom to explore in a technical and scientific environment. Partial validation of the achievements of the TAG is evidenced by the recent commencement of Phase 2 of the Forward Program, which requires the TAG to focus on defining, through further testing and analysis, the technical components of the preferred remediation option.

The Brukunga remediation Forward Program, incorporating the TAG, was only achievable if the community had confidence that both industry and Government would meet the environmental standards that they expected. "The public will most often judge the mining industry on the basis of its worst performers" (DITR, 2006). Inadequate mine closure poses environmental, health, safety and economic problems for all stakeholders, local communities, mining industry and government. Along with a commitment to ensuring that future mines meet the required environmental standards through a combination of both effective industry self-regulation and robust Government regulation activities, the remediation of past improprieties was an important part of generating that community confidence.

\section{Acknowledgements}

Special thanks to the following individuals for their valuable input and assistance: David Brett, Mike O'Kane, Peter Scott, Jeff Taylor and David Williams - members of the technical advisory group for the 
Brukunga Mine site remediation project. From PIRSA: Bev Voigt - administrative management; Paul Foster and Monica Redden - project and technical advisory group facilitation, framework facilitation; Molly Carrigan and Ross Stevens - project managers. Peter Grindley - mine site management, on-ground foreman.

\section{References}

Australian Nuclear Science and Technology Organisation (ANSTO) (1994) Oxidation rates in waste rock dumps and the tailings dam at Brukunga: A report to Environmental Geochemistry International Pty Ltd, ANSTO/C384, Sydney, Internal Report (unpublished).

Department of Industry Tourism and Resources (DITR) (2006) Mine Closure and Completion: Leading Practice Sustainable Development Program for the Mining Industry, Australian Government Department of Industry Tourism and Resources, Commonwealth of Australia, Canberra.

Environment Australia (EA) (1999) Environmental Risk Management: Best Practice Environmental Management in Mining, June, Environment Protection Agency, Canberra, p. 9.

Primary Industries and Resources of South Australia (PIRSA) (2001) Brukunga Mine Site Rehabilitation Rock Dump Relocation, Primary Industries and Resources of South Australia, South Australian Government, Adelaide, Report (unpublished). 